\title{
Dedifferentiated Liposarcoma in the Retroperitoneum in an Atomic Bomb Survivor: Report of a Case
}

\author{
Yukio Nakamura ${ }^{\mathrm{a}}$ Takeyoshi Yumiba $^{\mathrm{a}}$ Yoshio Yamasaki \\ Takuya Momiyama $^{a}$ Akira Ito $^{a}$ Yusuke Akamaru $^{a}$ \\ Tsutomu Kasugai ${ }^{\text {b }}$
}

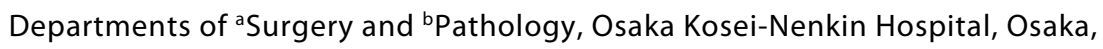
Japan

\section{Key Words}

Dedifferentiated liposarcoma - Malignant fibrous histiocytoma · Atomic bomb survivor

\begin{abstract}
A 76-year-old Japanese man was admitted to Kosei-Nenkin Hospital (Osaka, Japan) in November 2006; his chief complaint was a 10-kg loss in body weight over 3 months prior to admission. Abdominal computed tomography (CT) and dynamic magnetic resonance imaging (MRI) showed three masses in the retroperitoneum. The patient subsequently underwent surgery. The final histopathological diagnosis of tumors 1 and 2 was malignant fibrous histiocytoma of the retroperitoneum, and tumor 3 was a well-differentiated liposarcoma. By the presence of the liposarcoma, tumor 1 and 2 were thought to be the dedifferentiated areas of liposarcomas. At the age of 16, the patient had been exposed to radiation from the atomic bomb at Hiroshima towards the end of the Second World War. We postulate that in this case, radiation from the atomic bomb may have played an important role in the development of the sarcomas.
\end{abstract}

\section{Introduction}

Atomic bomb survivors are known to be at a high risk of developing various malignancies [1] containing sarcomas. We report a case of dedifferentiated liposarcoma in the retroperitoneum in an atomic bomb survivor. 


\section{Case Report}

A 76-year-old Japanese man was admitted to Kosei-Nenkin Hospital (Osaka, Japan) in November 2006; his chief complaint was a 10-kg loss in body weight over 3 months prior to admission. He had undergone appendectomy at age 10 and percutaneous transluminal coronary angioplasty at age 70 . At the age of 16, he had been exposed to radiation from the atomic bomb at Hiroshima towards the end of the Second World War. He did not have a family history of cancer. Physical examination showed a $10-\mathrm{cm}$ mass palpable on the right side of the abdomen, but no peripheral lymphadenopathy was observed.

Serum white blood cell count and C-reactive protein were elevated to 9,200/ $\mathrm{ll}$ and $4.94 \mathrm{mg} / \mathrm{dl}$, respectively. Carcinoembryonic antigen, carbohydrate antigen 19-9, cancer antigen 125 and alphafetoprotein showed no abnormalities. Abdominal computed tomography (CT) showed two 10-cm masses in the right side of the retroperitoneal space. Dynamic magnetic resonance imaging (MRI) showed two 10-cm masses (tumors 1 and 2) and another 5-cm mass (tumor 3) in the retroperitoneum ( $\underline{\text { fig. 1 })}$. Tumor 1 at the inferior pole of the kidney appeared as a ring-enhanced mass in the late phase. Its posterior side was enhanced in the late phase. Tumor 3 was not enhanced. A T1-weighted image showed a low signal intensity in tumors 1 and 2 but a high intensity in tumor 3. A T2-weighted image showed a high intensity in tumors 2 and 3 and a slightly high intensity at the center of tumor 1 . A positron emission tomography (PET) scan using fluorodeoxyglucose revealed slight uptake (SUV $\mathrm{Smax}_{\text {: }}$ early phase, 2.4; late phase, 2.8) at the border of tumor 1, and slight homogeneous uptake (SUV $\max$ : early phase, 2.5; late phase, 2.2) in tumor 2, suggestive of liposarcoma. Tumor 3 was not detected by PET (fig. 2). We were unable to establish tumor diagnosis, but we ascertained that these tumors might be malignant. Brain MRI and chest CT showed no metastasis.

The patient subsequently underwent surgery. We found that tumors 1 and 2 were present in the retroperitoneum, adjacent to the ascending colon. Tumor 3 was also present in the retroperitoneum and was located between the duodenum and the transverse mesocolon. The 3 tumors were resected with sufficient surgical margin.

Macroscopically, the cut surface of tumor $1(13 \times 10 \times 5 \mathrm{~cm}$, weight $460 \mathrm{~g})$ and tumor $2(12 \times 8 \times$ $6 \mathrm{~cm}$, weight $460 \mathrm{~g})$ was brown, glistening, and mucoid. That of tumor $3(6 \times 4 \times 4 \mathrm{~cm}$, weight $60 \mathrm{~g})$ was yellowish (ig. 3 ).

Microscopically, spindle fibroblast-like cells were arranged in a storiform pattern in tumors 1 and 2. Many mitotic figures and inflammatory cells were also found in these tumors (fig. 4a).

Immunohistochemical staining yielded positive results for vimentin, $\alpha 1$-antichymotrypsin (fig. $4 \mathrm{~b}$ ), and Mib-1 (50\%) (fig. 4c) and negative results for S-100, CD68, p53, and desmin. The final histopathological diagnosis of tumors 1 and 2 was malignant fibrous histiocytoma (MFH) of the retroperitoneum. Most parts of tumor 3 were composed of well-differentiated fat cells, which varied in size and shape, and a few lipoblasts were found, which had irregularly shaped nuclei and lipid droplets in their cytoplasm (fig. 4d). The final histopathological diagnosis of tumor 3 was well-differentiated liposarcoma. No residual tumor cells were observed on the resected surface of these 3 tumors.

The patient had an uneventful postoperative course. He was not administered chemotherapy or radiation therapy because of his heart disease and was discharged on the 14th postoperative day. It is now 13 months after surgery, and the patient is doing well without any evidence of recurrence or metastasis.

\section{Discussion}

MFH was first described as malignant histiocytoma and fibrous xanthoma by Ozello et al. [2] in 1963, and it was reported as malignant fibrous xanthoma by O'Brien and Stout [3] of the same group in 1964. Weiss and Enzinger [4] pointed out that MFH was the most common sarcoma in adults, and the concept of MFH arose based on their study conducted in 1978. MFH is classified as a group of soft tissue sarcomas composed of both histiocytic and fibrous elements arranged in a storiform pattern and accompanied by pleomorphic giant cells, xanthoma cells, and inflammatory cells. 
However, Coindre et al. [5] showed that in 17 of 25 cases in whom MFH in the retroperitoneum was initially diagnosed, dedifferentiated liposarcoma was the final diagnosis. Dedifferentiated liposarcomas have components of both well-differentiated liposarcoma and nonlipogenic sarcoma. They mainly occur in the retroperitoneal space, and the most common pattern in the dedifferentiated areas is that of high-grade pleomorphic MFH or storiform fibroblastic MFH [5]. Nowadays, many pathologists recognize that most so-called MFHs located in the retroperitoneum are dedifferentiated liposarcomas [6]. In our case, the immunohistochemical staining of tumors 1 and 2 yielded positive results for vimentin and al-antichymotrypsin, and the tumors were diagnosed as MFH. Tumor 3 was diagnosed as well-differentiated liposarcoma because most of it was composed of fatty tissue and few lipoblasts were observed. By the presence of the liposarcoma, tumors 1 and 2 were thought to be the dedifferentiated areas of liposarcomas. We finally diagnosed the present case as one of dedifferentiated liposarcoma in the retroperitoneum. Most area of tumor 3 was composed of adipocytes, which was the reason why tumor 3 was not detected in the preoperative PET scan.

Several studies showed that radiation therapy increases the relative risk of subsequent sarcomas [6,7]. Radiation-induced liposarcoma has been reported infrequently, but Orosz et al. [8] described the case of radiation-induced liposarcoma which showed dedifferentiation toward pleomorphic malignant fibrous histiocytoma. Atomic bomb survivors are known to have a high risk of developing various malignant and benign tumors [1]. A significantly high risk for cancers of the digestive system, breast, gastrointestinal tract, lung, skin, liver, ovary, urinary bladder, and other organs has been demonstrated in such persons [1]. The incidence of non-cancer diseases such as liver cirrhosis and myocardial infarction is also increased [9]. Preston et al. [10] demonstrated that the incidence of radiation-induced malignant tumors was $38 \%$ in atomic bomb survivors with irradiation doses ranging from 1 to $2 \mathrm{~Sv}$, and it was 59\% in survivors exposed to doses exceeding 2 Sv. Kamada et al. [11] reported that persons within $500 \mathrm{~m}$ from the hypocenter were exposed to irradiation doses ranging from 1.1 to $6.9 \mathrm{~Sv}$. The present patient was exposed to radiation within $500 \mathrm{~m}$ from the hypocenter, and the irradiation dose was estimated to be more than $1.1 \mathrm{~Sv}$. We postulate that in this case, radiation from the atomic bomb may have played an important role in the development of the sarcomas. 


\begin{tabular}{r|l|l|l} 
Case Reports in & $\begin{array}{l}\text { Case Rep Gastroenterol 2008;2:338-345 } \\
\text { D01: 10.1159/000151467 }\end{array}$ & Published online: September 30, 2008 & $\begin{array}{l}\text { O 2008 S. Karger AG, Basel } \\
\text { ISSN 1662-0631 } \\
\text { www.karger.com/crg }\end{array}$ \\
\hline
\end{tabular}

Fig. 1. MRI (T1-weighted image) showed the two 10-cm masses (tumors 1 and 2) (b) and another 5-cm mass (tumor 3) (a, c) in the retroperitoneum. A low signal intensity was detected in tumors 1 and 2, but a high intensity in tumor 3 .
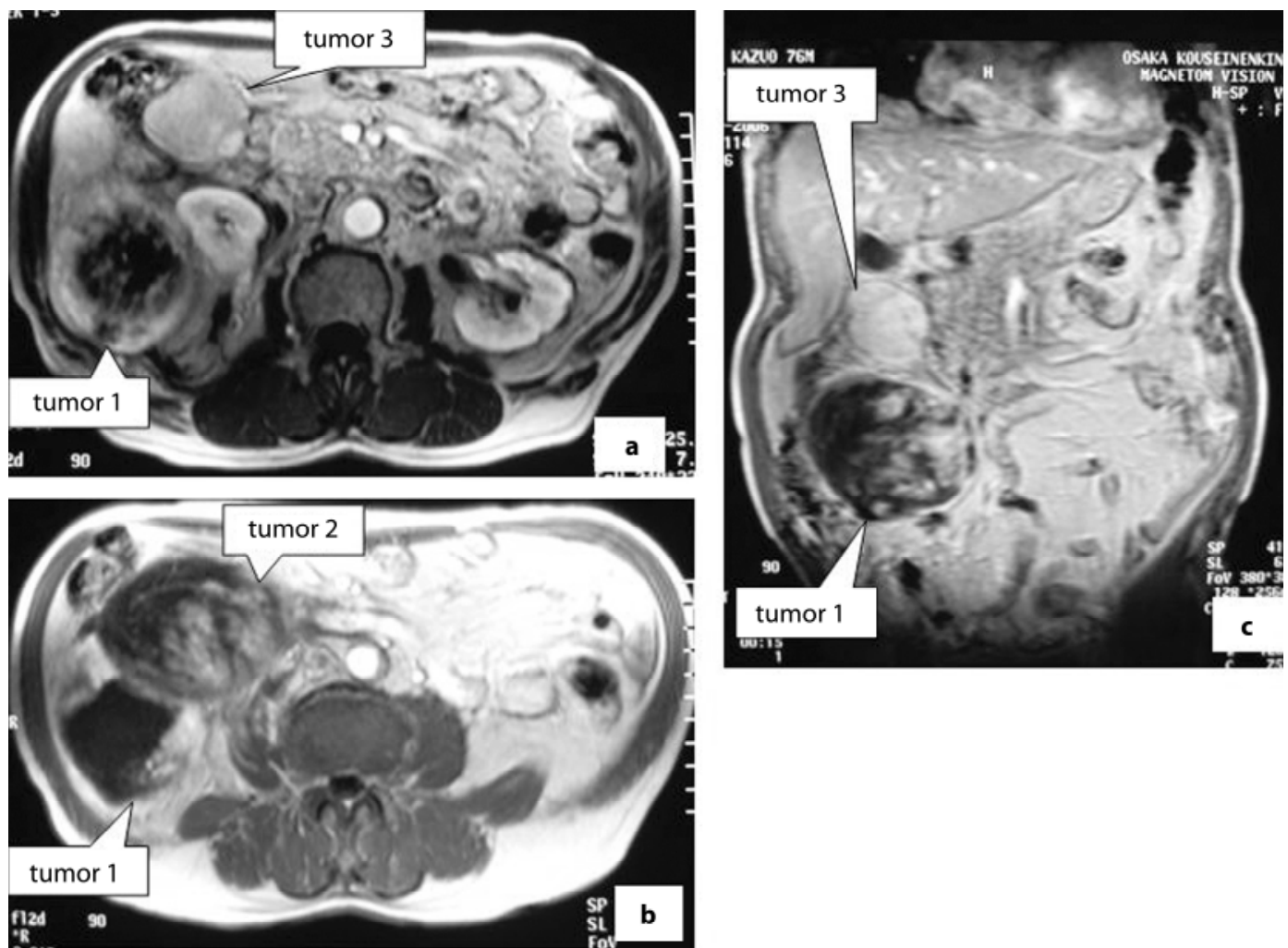
Fig. 2. A PET scan using fluorodeoxyglucose revealed slight uptake (SUV $\mathrm{max}_{\text {: }}$ early phase, 2.4; late phase, 2.8) at the border of tumor 1, and slight homogeneous uptake (SUV $\max$ : early phase, 2.5; late phase, 2.2) in tumor 2, suggestive of liposarcoma. Tumor 3 was not detected by PET.

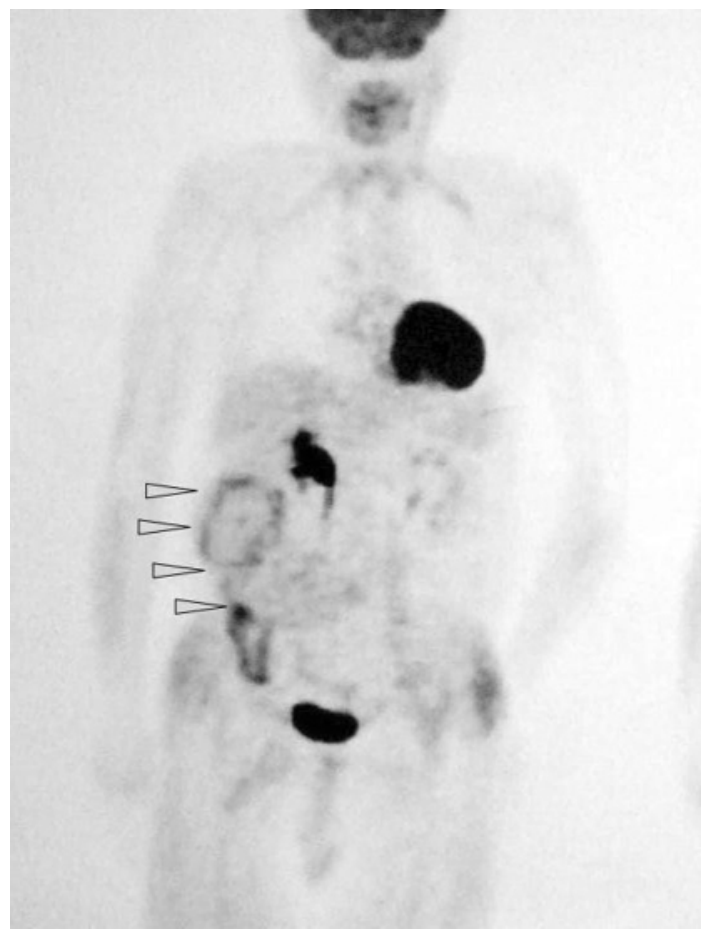




\begin{tabular}{r|l|l|l} 
Case Reports in & $\begin{array}{l}\text { Case Rep Gastroenterol 2008;2:338-345 } \\
\text { D0I: 10.1159/000151467 }\end{array}$ & Published online: September 30, 2008 & $\begin{array}{l}\text { @ 2008 S. Karger AG, Basel } \\
\text { ISSN 1662-0631 } \\
\text { www.karger.com/crg }\end{array}$ \\
\hline
\end{tabular}

Fig. 3. The three tumors in the retroperitoneum were resected with sufficient surgical margin (a). Macroscopically, the cut surfaces of tumor $1(13 \times 10 \times 5 \mathrm{~cm}$ in size, weight $460 \mathrm{~g})(\mathbf{b})$ and tumor 2 $(12 \times 8 \times 6 \mathrm{~cm}$, weight $460 \mathrm{~g})(\mathbf{d})$ were brown, glistening, and mucoid. That of tumor $3(6 \times 4 \times 4 \mathrm{~cm}$, weight $60 \mathrm{~g}$ ) (c) was yellowish.

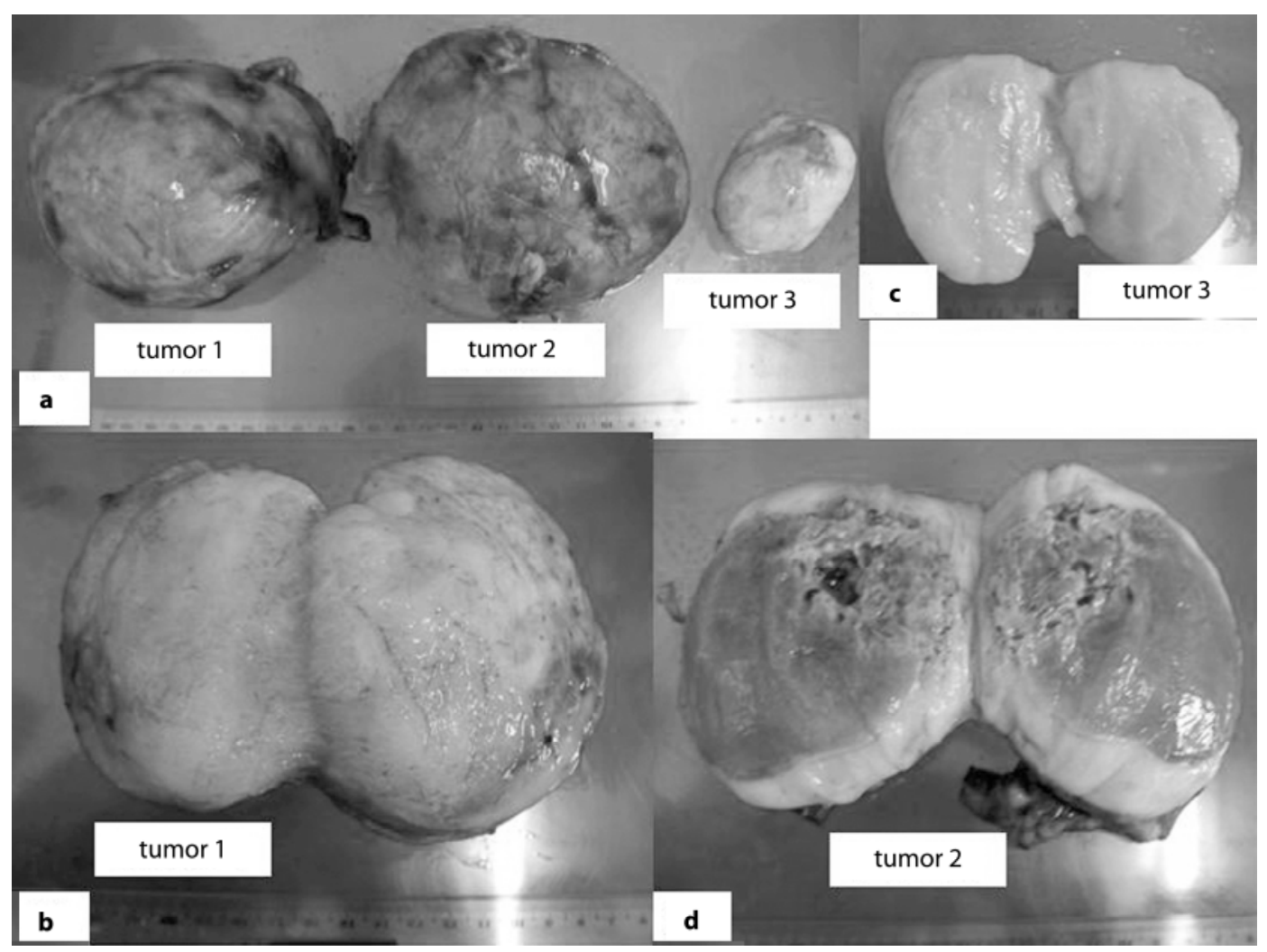




\begin{tabular}{r|l|l|l} 
Case Reports $h /$ & $\begin{array}{l}\text { Case Rep Gastroenterol 2008;2:338-345 } \\
\text { D01: 10.1159/000151467 }\end{array}$ & Published online: September 30, 2008 & $\begin{array}{l}\text { O 2008 S. Karger AG, Basel } \\
\text { ISSN 1662-0631 } \\
\text { www.karger.com/crg }\end{array}$ \\
\hline
\end{tabular}

Fig. 4. Microscopically, spindle fibroblast-like cells were arranged in a storiform pattern in tumors 1 and 2 (a). Immunohistochemical staining yielded positive results for vimentin, a1-antichymotrypsin (b), and Mib-1 (50\%) (c). Most parts of tumor 3 were composed of well-differentiated fat cells, and a few lipoblasts were found in tumor $3(\mathbf{d})$.

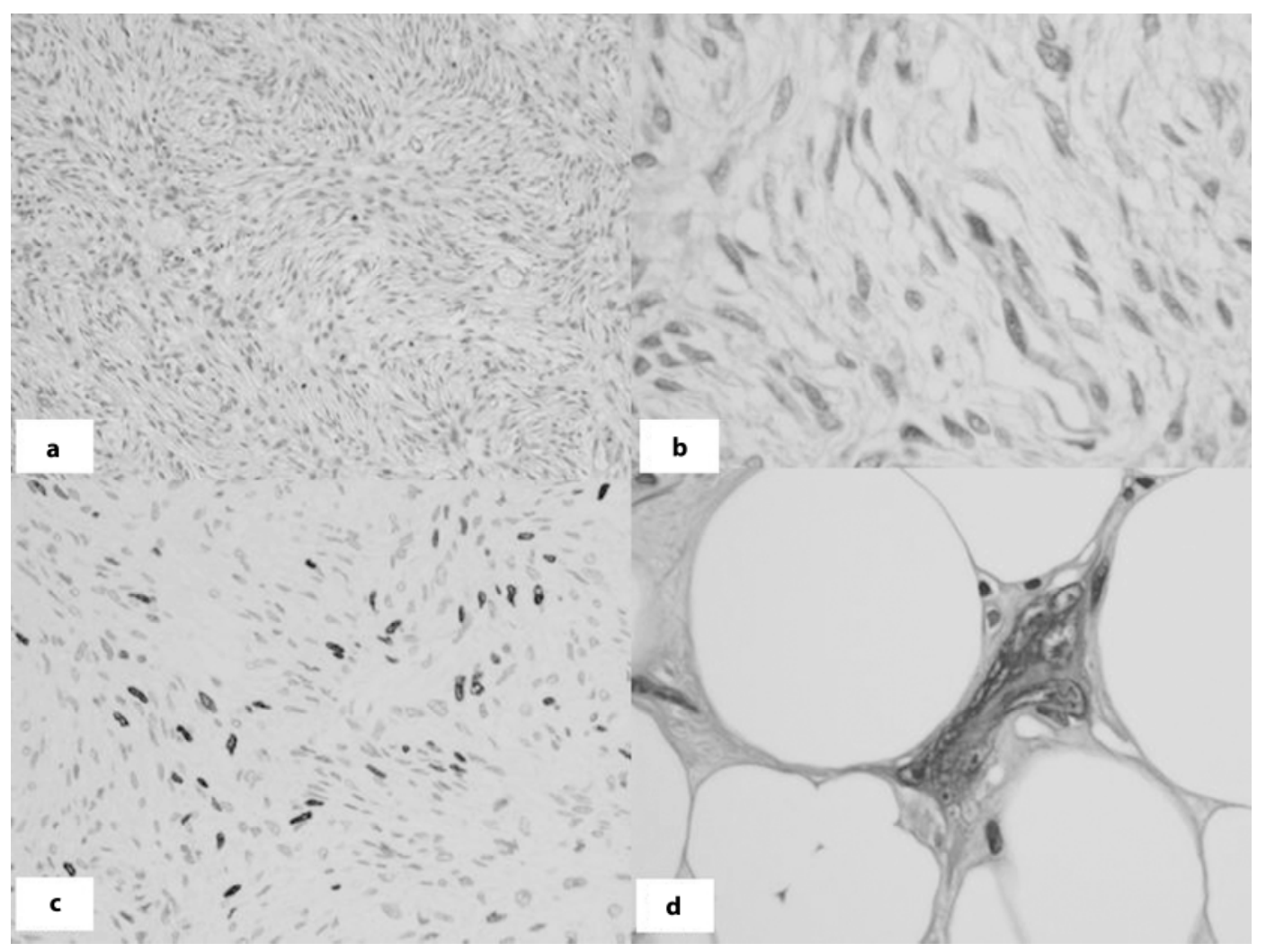




\section{References}

1 Ron E, Preston DL, Mabuchi K, Thompson DE, Soda M: Cancer incidence in atomic bomb survivors. Part IV: Comparison of cancer incidence and mortality. Radiat Res 1994;137(suppl 2):98-112.

-2 Ozello L, Stout AP, Murray MR: Cultural characteristics of malignant histiocytomas and fibrous xanthomas. Cancer 1963;16:331-344.

-3 O'Brien JE, Stout AP: Malignant fibrous xanthomas. Cancer 1964;17:1445-1455.

-4 Weiss SW, Enzinger FM: Malignant fibrous histiocytoma: an analysis of 200 cases. Cancer 1978;41:2250-2266.

5 Coindre JM, Mariani O, Chibon F, et al: Most malignant histiocytomas developed in the retroperitoneum are dedifferentiated liposarcomas: a review of 25 cases initially diagnosed as malignant fibrous histiocytoma. Mod Pathol 2003;16:256262.

-6 Amendola BE, Amendola MA, McClatchery KD, Miller CH: Radiation-associated sarcoma: a review of 23 patients with postradiation sarcoma over a 50 year period. Am J Clin Oncol 1989;12:411-415.

7 Karaparkar AP, Pandya SK, Desai AP: Radiation-induced sarcoma. Surg Neurol 1980;13:419-422.

-8 Orosz Z, Rohonyi B, Luksander A, Szántó J: Pleomorphic liposarcoma of a young woman following radiotherapy for epithelioid sarcoma. Pathol Oncol Res 2000;6:287-291.

$\checkmark 9$ Wong FL, Yamada M, Sasaki H, et al: Noncancer disease incidence in the atomic bomb survivors: 1958-1986. Radiat Res 1993;135:418-430.

10 Preston D, Shimizu Y, Pierce D, Suyama A, Mabuchi K: Studies of mortality of atomic bomb survivors. Report 13: solid cancer and noncancer disease mortality: 1950-1997. Radiat Res 2003;160:381-407.

11 Kamada N, Kimura A, Hayakawa N: Synthetic medical studies on atomic bomb survivors exposed in short distances from the hypocenter XXVIII; atomic bomb survivors' life for the 60 years after bombing (in Japanese). Hiroshima-Igaku 2006;59:352-356. 